\title{
Reassessing the Regulation of High-Risk Medical Device Cases
}

Robert L. Rabin

Alyssa J. Picard

Follow this and additional works at: https://via.library.depaul.edu/law-review

Part of the Law Commons

\section{Recommended Citation}

Robert L. Rabin \& Alyssa J. Picard, Reassessing the Regulation of High-Risk Medical Device Cases, 68 DePaul L. Rev. (2019)

Available at: https://via.library.depaul.edu/law-review/vol68/iss2/8

This Article is brought to you for free and open access by the College of Law at Digital Commons@DePaul. It has been accepted for inclusion in DePaul Law Review by an authorized editor of Digital Commons@DePaul. For more information, please contact digitalservices@depaul.edu. 


\title{
REASSESSING THE REGULATION OF HIGH-RISK MEDICAL DEVICE CASES
}

\author{
Robert L. Rabin* and Alyssa J. Picard**
}

\section{INTRODUCTION}

Beginning in the mid-1960s, there was a surge of federal legislative activity aimed at regulation of health and safety concerns. ${ }^{1}$ By 1972 , this wave had more or less ended its surge and retreated to an implementation phase. Strikingly, medical device regulation had been passed by. But not for long. In 1976, Congress enacted the Medical Device Amendments (MDA), plugging a gap between regulation of prescription drugs, which were subjected to a premarket protocol aimed at assuring safety and efficacy, and medical devices, which were solely monitored for adulteration and misbranding after distribution in the marketplace. ${ }^{2}$

Somewhat earlier, this system had revealed itself to be less than adequate. The Study Group on Medical Devices (the "Cooper Committee"), convened in 1969 by the Secretary of Health, Education, and Welfare, had published a report the following year pointing to 10,000 injuries and 751 deaths from medical devices over the previous decade, and the Committee recommended replacing the current system with a dedicated regulatory regime for devices. ${ }^{3}$ Meanwhile, the Dalkon Shield intrauterine device served as a high-profile symbol of the failures of the previous system after it was pulled from the market

* A. Calder Mackay Professor of Law, Stanford Law School.

** Stanford Law School Class of 2020.

1. See Robert L. Rabin, Federal Regulation in Historical Perspective, 38 Stan. L. Rev. 1189, 1248 (1986).

2. "The Federal Food, Drug, and Cosmetic Act of 1938 authorized the FDA to seize adulterated or misbranded devices and to seek injunctions or criminal prosecutions against manufacturers or distributors of violative articles," but this meant that the FDA bore the burden of proving each item was unsafe, and that regulation often came after the fact of injury and at the expense of considerable agency time and resources. Robert B. Leflar, Public Accountability and Medical Device Regulation, 2 Harv. J.L. \& TECH. 1, 6 (1989).

3. Study Grp. on Med. Devices, Dep't of Health, Educ. \& Welfare, Medical Devices: A Legislative Plan (1970). See also U.S. Gov't Accountability Off., GAO/HRD83-53, Federal Regulation of Medical Devices-Problems Still to Be Overcome 2, 20 (1983). 
in 1974 following reports of infections, injuries, and deaths-for a total of over 300,000 complaints. ${ }^{4}$ The MDA was Congress's response.

Since the implementation of the 1976 regime, medical devices are classified by risk-level and intended use into three categories, which determine the stringency of the regulations and the premarket approval processes to which the devices must adhere.

Class I devices present "minimal potential for harm" and are simple in design; they include things like tongue depressors, elastic bandages, and bedpans. ${ }^{5}$ They currently represent about $47 \%$ of medical devices. ${ }^{6}$

Class II devices are more complex, but still not life-sustaining - they include devices such as powered wheelchairs and pregnancy test kits, and they encompass $43 \%$ of medical devices. ${ }^{7}$

Class III devices "usually sustain or support life, are implanted, or present potential unreasonable risk of illness or injury;" they represent the remaining $10 \%$ of medical devices and include devices like pacemakers, breast implants, and intrauterine devices. ${ }^{8}$

There are general requirements the U.S. Food and Drug Administration (FDA) sets for all devices, including those not subject to clinical testing. ${ }^{9}$

4. A number of books have been written on the Dalkon Shield claims. See, e.g., Morton Mintz, At Any Cost: Corporate Greed, Women, and the Dalkon Shield (1985).

5. Learn If a Medical Device Has Been Cleared by FDA for Marketing, U.S. Food \& DRUG Admin., https://www.fda.gov/MedicalDevices/ResourcesforYou/Consumers/ucm142523.htm (last updated Dec. 29, 2017).

6. $I d$.

7. $I d$.

8. Id.

9. All devices must adhere to "general controls," which include basic regulations governing proper labeling, manufacturer registration, and manufacturing quality control. See 21 U.S.C. $\S 360$ c(a)(1)(A)(i) (2012). Class II devices are subject to additional "special controls," including post-market surveillance, patient registries, and performance standards promulgated for specific devices. Id. $\S 360$ c(a)(1)(B). Despite these requirements, most Class I devices (95\%) and some Class II devices fall into generic categories of exempted devices, meaning neither a $510(\mathrm{k})$ premarket notification application nor further analysis is required to market them. Class I/II Exemptions, U.S. Food \& Drug Admin., https://www.fda.gov/MedicalDevices/DeviceRegula tionandGuidance/Overview/ClassifyYourDevice/ucm051549.htm (last updated Mar. 22, 2018). The FDA is authorized to designate these types of exempt generic devices by $\S 513(\mathrm{~d})(2)(\mathrm{A})$ of the FDCA (codified as 21 U.S.C. $\$ 360 \mathrm{c}(\mathrm{d})(2)(\mathrm{A})$ ), and defines these categories in 21 C.F.R. $\S \S 862-892$ (2018). For all exempt devices, the manufacturer still must register their establishment and list their generic product with the FDA.

Likewise, all devices must conform to the current "Good Manufacturing Practices" (GMP), which the FDA may promulgate after taking recommendations from an advisory committee and holding an oral hearing on any proposed regulations (individual manufacturers may still petition for an exemption or variance from these regulations). 21 U.S.C. $§ 360 j(f)$ (2012). Since 1996, these have been laid out in 21 C.F.R. $§ 820$ (2018). 
Only Class III devices are required to go through the premarket approval process (PMA) - a process that requires clinical data. ${ }^{10}$ In a leading case on the preemption of tort claims, Riegel v. Medtronic, Inc., ${ }^{11}$ the U.S. Supreme Court had occasion to review the rigor of PMA premarketing oversight and concluded that it was indeed notable for its scrupulousness. ${ }^{12}$ On average, the Court noted, the FDA spent 1,200 hours reviewing an application, which included reports of every study and investigation of the device, a description of compo-

Class I and II devices are also subject to premarket notification requirements, wherein the manufacturer must register with the FDA its intent to market a device and submit an application describing the device, the class to which the device belongs, proposed labeling, and a description of the actions taken to comply with the applicable requirements. The FDA then engages in a limited form of review to determine whether the device is "substantially equivalent" to a preexisting legally marketed device. If so, no further regulatory analysis is required before the devices can enter the market. This is known as the $510(\mathrm{k})$ clearance process. Many commentators have noted that the $510(\mathrm{k})$ process offers a very low bar for manufacturers to meet; it is generally completed quickly and only very rarely results in the rejection or delay of a device. See, e.g., Lewis v. Johnson \& Johnson, 991 F. Supp. 2d 748, 753 (S.D. W. Va. 2014) (noting that an average 510(k) review process takes only 20 hours); Robert Adler, The 1976 Medical Device Amendments: A Step in the Right Direction Needs Another Step in the Right Direction, 43 Food Drug Cosm. L.J. 511, 516 (1988) (“A 510(k) notification requires very little information, rarely elicits a negative response from the FDA, and gets processed very quickly.”); Marilyn Uzdavines, Dying for a Solution: The Regulation of Medical Devices Falls Short in the 21st Century Cures Act, 18 NEv. L.J. 629, 641 (2018) ("[T]he focus is on equivalence rather than safety.").

10. Even for Class III devices, however, there are exceptions to PMA review. For example, in passing the MDA in 1976, Congress did not suddenly require all medical devices already on the market to be made unavailable and subjected to PMA review. Instead, a "grandfather clause" was written into the statute, which allowed any "pre-amendments device" (i.e., a device legally marketed in the United States by a firm before May 28, 1976) to stay on the market, provided that it had not been significantly changed or modified since before May 28, 1976 and that the FDA had not published a regulation specifically requiring a PMA application for that particular device. Premarket Notification (510k), U.S. Food \& DRUG ADmIN., https://www.fda.gov/medical devices/deviceregulationandguidance/howtomarketyourdevice/premarketsubmissions/premarket notification510k/default.htm\#preamend (last updated Sept. 27, 2018).

As a result, no studies, clinical data, or further marketing approval was necessary for devices which predated FDA's modern regulatory regime. This remains true even if a pre-amendments device is classified as Class III. Special Considerations, U.S. Food \& Drug Admin., https://www .fda.gov/MedicalDevices/DeviceRegulationandGuidance/HowtoMarketYourDevice/Premarket Submissions/PremarketNotification510k/ucm134578.htm (last updated Jan. 22, 2019).

Although Congressional intent in including this provision in the MDA seems to have been for the FDA to eventually promulgate regulations providing for the PMA applications for the various pre-amendment devices, the FDA has been slow to do so. U.S. Gov'T Accountability Office, GAO-09-90, FDA Should Take Steps to Ensure That High-Risk Device Types Are Approved Through the Most Stringent Premarket Review Process 10-11 (2009) [hereinafter GAO-09-90]. There remain many types of pre-amendment Class III devices for which the FDA has neither issued a reclassification nor published regulations requiring PMA submissions. Id. at 16, 20. FDA officials have acknowledged that these actions are important and have yet to be taken, but there is no set time frame for doing so. Id. at 23.

For additional exceptions to PMA review, see infra Parts I.A, D, and E.

11. 552 U.S. 312 (2008).

12. Id. at 317-18. 
nent parts, samples of products, a specimen of the proposed labeling, and descriptions of the production, manufacturing, packaging, and installation methods. ${ }^{13}$ As part of the PMA process, the FDA had discretion to bring in a panel of outside experts and could request more information or data from the manufacturer. ${ }^{14}$

Viewing the process through this lens, the Court preempted the plaintiff's tort claim, which was based on failure to adequately warn of the risk that defendant manufacturer's balloon catheter would rupture during angioplasty surgery-a risk that came to fruition. According to the Court, Section 360k of the MDA-an express preemption clause barring "any requirement ... which is different from, or in addition to, any requirement ... [under the Act] which relates to the safety or effectiveness of the device ...."-was applicable to the claim. ${ }^{15}$

A sharp line was drawn between the PMA process in Riegel and FDA's $510(\mathrm{k})$ substantial equivalence review, which only subjects a device to a limited form of review to determine whether it is "substantially equivalent" to a preexisting legally marketed device. ${ }^{16}$ Twelve years earlier, in Medtronic, Inc. v. Lohr, ${ }^{17}$ the Supreme Court found substantial equivalence review insufficiently rigorous to preempt tort claims. Taken together, the two decisions seemed to mark out a persuasive boundary between tort claims that would, if allowed, impermissibly re-tread the same ground covered by the agency (via the PMA process), and claims premised on a risk/utility tort process complementary to the once-over-lightly of "substantial equivalence" review. ${ }^{18}$

In this Article, Part I probes more deeply into the case for recognizing a safe harbor from tort claims under the existing regime of FDA premarket assessment of high-risk devices. ${ }^{19}$ Part II addresses postmarket FDA strategies for assessment of product safety. Part III shifts the focal point to tort, revisiting the shadow cast by preemption over

13. Id. at 318. See also 21 U.S.C. $\S 360 \mathrm{e}(2012)$.

14. 21 C.F.R. $\$ 814.44(\mathrm{a})$ (2018).

15. 21 U.S.C. $\$ 360 \mathrm{k}$ (2012); Riegel, 552 U.S. at 316.

16. 21 C.F.R. $\$ 807.81-97$ (2018). See discussion supra note 9 and infra Part I.A.

17. 518 U.S. 470 (1996).

18. Indeed, I took this position in Robert L. Rabin, Conflicting Conceptions of Tort Preemption: Territorial Claims in the Domain of Accidental Harm, 74 Brook. L. Rev. 987 (2009).

19. Although the PMA process is required by default for all high-risk (Class III) devices, in actuality it is only triggered for a small minority of devices that go to market-currently, only $1 \%$ of all devices go through the PMA process. See Rita Redberg, Medical Device Recalls: Get It Right the First Time, 171 Archives Internal Med. 1011, 1011 (2011). As noted above, approximately $90 \%$ of devices fall into Classes I and II, and so were never subject to the PMA requirement; the remaining $9 \%$, however, are Class III devices that fall under some exception to PMA review. 
tort as a complementary regulatory strategy. Finally, Part IV offers concluding thoughts on the necessity of a fresh look at the regulatory process in action-and reconsideration of how it might be improved in this vital area of health and safety.

\section{The Premarket Approval Process: Looking Beneath the Surface}

\section{A. 510(k) Review}

More explicitly, with reference to Lohr and the substantial equivalence exception to PMA review, the plaintiff's defective design claim was based on injury from the malfunctioning of a pacemaker inserted to correct a cardiac irregularity. Under the substantial equivalence provision, the pacemaker was fast-tracked because of its similarity to other such devices already on the market. In other words, there was no evidence-based, risk/benefit inquiry by the FDA focused on the precise design of the defendant's pacemaker. As a consequence, there was no basis for a preemption defense claiming that the tort suit would be going over the same ground as the agency regulatory approval process. This carve-out from the statutory preemption clause seemed to the Supreme Court consistent with the strictures of the Supremacy Clause. ${ }^{20}$ And so matters stood in the Court for more than a decade, until Riegel-addressing a tort claim in the context of PMA approval-animated successful recourse to the statutory preemption clause.

Critically, one should note that the FDA relies on the $510(\mathrm{k})$ substantial equivalence process in a considerable number of cases involving Class III medical devices. ${ }^{21}$ Hence, whatever limitations Riegel might place on the role of tort in high-risk PMA medical device cases, Lohr does stand for tort liability as a potential sanction when injuries result from devices that never underwent focused, evidence-based regulatory scrutiny.

\section{B. Safe Harbor/Troubled Waters}

But does Riegel, extolling the safeguards of PMA review-and concomitantly creating a safe harbor from tort claims-in fact set a territorial boundary that creates confidence that optimal safety and

20. U.S. Const. art. VI, $\S 1$.

21. In fiscal years 2003 through 2007, the FDA reviewed 342 submissions for Class III devices through the $510(\mathrm{k})$ process and cleared 228 of them; reviewed 784 supplemental PMA applications and cleared 664 of them; and reviewed only 217 original PMA applications and cleared 170 of them. GAO-09-90, supra note 10 , at 6 . 
efficacy is being monitored by the agency? As the following will suggest, there is room for substantial doubt. ${ }^{22}$ Beneath the surface gloss of procedural regularity that so enamored the Court, several studies of the clinical data that serve as inputs to the FDA review and approval process reveal a disquieting picture. ${ }^{23}$

In a 2009 systematic review of PMA studies for high-risk cardiovascular devices (which included 123 studies of 78 devices), it was found that only $27 \%$ of the studies were randomized and only $14 \%$ were blinded. ${ }^{24}$ Study participants were $66.9 \%$ male and $87 \%$ white, likely indicating study populations that are not representative of actual patients using the devices once they are on the market. ${ }^{25}$ Furthermore, of the 78 devices studied, the majority of them $(65 \%)$ received premarket approval after being supported by only a single study. ${ }^{26}$

Another study, in 2015, examined 286 clinical studies associated with 28 devices that received FDA approval in 2010 and 2011. The 2015 study found that all of the premarket studies included were industry-funded, approximately $60 \%$ of the post-market follow-up studies were industry-funded, roughly $75 \%$ were unblinded, and nearly $50 \%$ were single-group and therefore had no comparator. ${ }^{27}$ In particular, the "pivotal studies" (so-called because they are meant to prove the safety and effectiveness required of the device for a successful PMA application) in that sample "generally enrolled fewer than 300 patients and were often designed without blinding, comparators, or primary end point follow-up exceeding 1 year." 28 In general, the authors concluded that "the amount and quality of evidence generated over [a] total product lifecycle varies widely," and that "premarket

22. In this regard, I expand on the clinical process observations in Rita F. Redberg, Improving the Safety of High-Risk Medical Devices, 68 DePAul L. Rev. 327 (2019) [hereinafter Redberg, Improving the Safety of High-Risk Medical Devices].

23. As Dr. Redberg notes:

Discovering a safety problem with an implanted device carries a greater risk for patients. Unlike a drug discovered to be associated with adverse events, which can simply be stopped, an implanted device must either be removed in a risky procedure or left in the body with the attendant risk. Thus, high-quality RCTs to assure safety and effectiveness for high-risk devices prior to approval would go a long way to improve patient safety and to ensure we are not recommending unnecessary or harmful devices to patients.

Id. at 331 .

24. Sanket S. Dhruva et al., Strength of Study Evidence Examined by the FDA in Premarket Approval of Cardiovascular Devices, 302 JAMA 2679, 2680 (2009).

25. Id.

26. Id.

27. Vinay K. Rathi et al., Characteristics of Clinical Studies Conducted Over the Total Product Life Cycle of High-Risk Therapeutic Medical Devices Receiving FDA Premarket Approval in 2010 and 2011, 314 JAMA 604, 608-09 (2015).

28. Id. at 610 . 
studies provide limited data to address important clinical questions that often arise after approval, including those related to long-term device performance, new indications or iterations, and safety and effectiveness in real-world populations." 29

Especially for implantable devices that are designed to be used over a long period of time, the data collected through these studies may be insufficient for making optimal regulatory and clinical decisions. ${ }^{30} \mathrm{But}$ the Riegel Court is quite clear that it is not about to second-guess the FDA's stamp of approval once it has been assured that the manufacturer has dutifully complied with the PMA regulatory specifications. Nonetheless, a straightforward challenge to the foundational premise of the Riegel decision is not necessarily the only pathway to reassessing and refining the case for preemption.

\section{New Evidence}

In her Riegel dissent, Justice Ginsburg alludes to a scenario that was neither presented nor discussed in the majority opinion:

The Court's holding does not reach an important issue outside the bounds of this case: the preemptive effect of $360 \mathrm{k}(\mathrm{a})$ where evidence of a medical device's defect comes to light only after the device receives premarket approval. ${ }^{31}$

This is indeed a critical issue. Conflict preemption rests on the premise that a tort suit would be improperly reexamining the evidencebased determination that served as the foundation for regulatory approval. As such, a finding that substantial new evidence of risks associated with the device arose after regulatory approval—risks which have not been addressed post-approval by the agency-suggests that the

\section{Id.}

30. An additional concern is that there are some notable disconnects between some of the FDA summaries of the clinical studies that support successful PMA applications and the same studies when they are later published-suggesting that medical device companies might engage in selective reporting of data when they submit their PMA applications to the FDA. One report on this issue examined 106 cardiovascular devices that received approval based on PMA applications between 2000 and 2010, after being supported by 177 clinical studies. Lee Chang et al., Selective Reporting in Trials of High Risk Cardiovascular Devices: Cross Sectional Comparison Between Premarket Approval Summaries and Published Reports, 350 Brit. MED. J. h2613 (2015). The authors found that as of January 2013, only $49 \%$ of those studies had been separately published. Id. Amongst those trials that had been published, a significant number of them "differ[ed] substantially" in study population, primary endpoints, and results from the data submitted to the FDA as part of the PMA process. Id. Besides the conclusion that selective reporting might be weakening the efficacy of the PMA process, the report also highlights the related issue of the lack of scientific transparency throughout the process. With only $49 \%$ of the studies resulting in peer-reviewed publications, it remains impossible to assess the gravity of the problem of selective reporting in the majority of PMA applications.

31. Riegel v. Medtronic, Inc., 552 U.S. 312, 333 n.1 (2008) (Ginsburg, J., dissenting). 
plaintiff's tort claim is beyond the reach of the preemption provision. ${ }^{32}$

\section{PMA Supplements}

Moreover, the formal character of the PMA process, as set out in Riegel, is at odds with medical device marketing practices in the real world. If a Class III device has been subjected to modification since receiving PMA certification, the modified device can be approved through a less rigorous procedure known as a "PMA supplement," 33 which has fewer evidence and data requirements than an original PMA. Most notably, it generally does not require any new clinical data to account for the modifications. ${ }^{34}$ This path remains open even if a device has gone through many iterations of changes; indeed, "almost all PMA devices" accumulate several, and often hundreds, of supplements. ${ }^{35}$

In addition to the lack of additional clinical data requirements, the PMA supplement process is also notable because it involves only piecemeal evaluation: each submitted supplement application for a given device is evaluated separately. This means that a company can submit modifications to a device one PMA supplement at a time, rather than including all of the modifications in a single application. ${ }^{36}$ This process "makes it difficult, if not impossible, to take into account the cumulative effects and interactions of multiple modifications," and it may result in a device on the market that differs significantly from the one that was subject to clinical testing in the original PMA process. ${ }^{37}$ The piecemeal nature of the supplement process also means that there can be many different models of an original PMA device left on the market at once, and it can be "virtually impossible" for physicians to track and understand which supplemental modifications apply to which model. ${ }^{38}$

32. See Rabin, supra note 18 , at 1001-02.

33. 21 C.F.R. $\$ 814.39$ (2018). See also PMA Supplements and Amendments, U.S. Food \& Drug Admin., https://www.fda.gov/MedicalDevices/DeviceRegulationandGuidance/HowtoMar ketYourDevice/PremarketSubmissions/PremarketApprovalPMA/ucm050467.htm (last updated Dec. 14, 2018).

34. Sarah Zheng \& Rita Redberg, Premarket Approval Supplement Pathway: Do We Know What We Are Getting?, 160 Annals Internal Med. 798 (2014).

35. Id.

36. Id.

37. Id.

38. Id. 


\section{E. Humanitarian Devices}

If a Class III device is meant to treat a rare condition or disease, it can fall into another exception to the PMA process known as the $\mathrm{Hu}-$ manitarian Device Exemption (HDE). ${ }^{39}$ The HDE process is similar to PMA review, but, crucially, the efficacy requirements are lower. Instead, the FDA requires that devices approved under this exemption show a "probable benefit" in clinical trials on a small number of patients. ${ }^{40}$

In order to be considered for this exemption, comparable devices must not be available through any other FDA pathway; the device must not pose an "unreasonable risk of illness or injury;" and its "probable benefit must outweigh its risks." ${ }_{11}$ The 21st Century Cures Act of 2016 expanded the limits of this program: Currently, devices eligible for this exemption should be intended to treat or diagnose diseases or conditions affecting no more than 8,000 U.S. patients (an increase from the previous 4,000-patient limitation). ${ }^{42}$ As part of the assessment for these devices, the FDA is to consider the target patient population and size, as well as the device's intended use and existing treatment options. ${ }^{43}$ Under the FDA Reauthorization Act of 2017,44 either an Institutional Review Board or an "appropriate local committee" can approve a humanitarian use device under this exemption..$^{45}$ Since this process was implemented in 1990, 72 devices have been brought to market through the humanitarian device exemption. ${ }^{46}$

If this array of premarketing approval processes falls short of assuring optimal patient safety and efficacy, it might nonetheless be backstopped by effective monitoring of device performance through postmarketing assessment. On this score, consider the following.

39. See 21 C.F.R. $\$ \$ 814.100-126$ (2018).

40. Humanitarian Device Exemption (HDE) Program: Draft Guidance for Industry and Food and Drug Administration Staff, U.S. Food \& Drug Admin. 15-17 (June 13, 2018), https://www .fda.gov/downloads/medicaldevices/deviceregulationandguidance/guidancedocuments/ucm 3892 75.pdf.

41. Ari Gartenberg et al., Presumed Safe No More: Lessons from the Wingspan Saga on Regulation of Devices, 348 BRIT. MED. J. g93 (2014).

42. Ana Mulero, FDA Clarifies Humanitarian Device Exemption Policies, Reg. Aff. Prof. Soc'y (June 12, 2018), https://www.raps.org/news-and-articles/news-articles/2018/6/fda-drafts-de sign-of-for-humanitarian-device-exemp.

43. Id.

44. Pub. L. No. 115-52, 131 Stat. 1005 (codified at 21 U.S.C. $§ 360 j(m)$ (Supp. V 2018)).

45. The FDA is currently soliciting comments on the requirements of such a committee for the HDE program.

46. Listing of CDRH Humanitarian Device Exemptions, U.S. Food \& Drug Admin., https:// www.fda.gov/MedicalDevices/ProductsandMedicalProcedures/DeviceApprovalsandClearances/ HDEApprovals/ucm161827.htm (last updated Sept. 17, 2018). 


\section{Post-Marketing Strategies for Assessing Product SAfety}

\section{A. Post-Approval Studies}

At the time it approves a manufacturer's PMA application or when approving a device through the HDE process, the FDA may order the manufacturer to conduct a post-approval study (PAS). ${ }^{47}$ Under reforms introduced by the Safe Medical Devices Act, ${ }^{48}$ the FDA may also order a "post-market surveillance study" of a device (this time, including those not only from the PMA and humanitarian device pathways but also those approved through the 510(k) pathway). Amongst other triggering conditions, such a study is warranted when the device's failure would be "reasonably likely to have serious adverse health consequences," and when FDA officials identify a potential issue with a device through adverse event reports or reviews of scientific literature. ${ }^{49}$

The FDA has indicated that it would like to strengthen the PAS system; in 2013, it issued a strategic plan titled "Strengthening Our National System for Medical Device Postmarket Surveillance."50 And indeed, it has ordered manufacturers to complete hundreds of PASs over the past few years: 223 PASs for 158 devices that had been approved between 2005 and 2011.51 During that six-year period, about half the PMA applications approved had a PAS requirement. ${ }^{52}$ However, these orders are not necessarily translating into high-quality follow-up data. At the time of a 2014 study, only $26 \%$ of the 223 PASs ordered between 2005 and 2011 had been completed; 53 despite this, the FDA has never issued a warning letter or penalty due to study

47. Ian S. Reynolds et al., Assessing the Safety and Effectiveness of Devices After U.S. Food and Drug Administration Approval: FDA-Mandated Postapproval Studies, 174 JAMA INTERNAL Med. 1773, 1774 (2014); U.S. Gov't Accountability Office, GAO-15-815, FDA Ordered Postmarket Studies to Better Understand Safety Issues, and Many Studies Are ONGOING 4 (2015) [hereinafter GAO-15-815].

48. Pub. L. No. 101-629, § 522, 104 Stat. 4511, 4521 (codified at 21 U.S.C. $\$ 3601$ (2012)).

49. Postmarket Surveillance Under Section 522 of the Federal Food, Drug, and Cosmetic Act: Guidance for Industry and Food and Drug Administration Staff, U.S. Food \& Drug Admin. 4-6 (May 16, 2016), https://www.fda.gov/downloads/MedicalDevices/DeviceRegulationandGuid ance/GuidanceDocuments/ucm268141.pdf.

50. Strengthening Our National System for Medical Device Postmarket Surveillance: Update and Next Steps, U.S. Food \& Drug Admin., https:/www.fda.gov/downloads/MedicalDevices/ Safety/CDRHPostmarketSurveillance/UCM348845.pdf [http://wayback.archive-it.org/7993/2017 0406001015/https:/www.fda.gov/downloads/MedicalDevices/Safety/CDRHPostmarketSurveil lance/UCM348845.pdf] (last visited Jan. 31, 2019).

51. Reynolds et al., supra note 47 , at 1775 .

52. Id.

53. Id. at 1776 . 
delays, inadequate progress, or any other issues related to the PAS requirements. ${ }^{54}$ This is potentially a serious problem, as it does appear that completed PASs can alter clinical or regulatory guidance: $53 \%$ of the completed PASs caused the FDA to request a labelling change for the relevant device, and at least one PAS uncovered results that caused the FDA to remove the device from the market entirely. ${ }^{55}$

The Government Accountability Office (GAO) performed a similar study in 2015, this time looking at both the PASs and the post-market surveillance studies ordered between 2007 and 2015.56 Among the PASs, it found that $20 \%$ had been completed and $72 \%$ were still categorized as ongoing (with an additional $8 \%$ inactive due to circumstances like the device no longer being on the market). ${ }^{57}$ Of the 225 PASs identified as "ongoing," 43 of them (19\%) were delayed. ${ }^{58}$ Both sets of "adequately progressing" and "delayed" studies had been ongoing for an average of a little over three years each. ${ }^{59}$

Among the 392 post-market surveillance studies ordered during a similar time period, $88 \%$ were categorized as inactive. Of these, $31 \%$ had been consolidated into a single study (so work might still be ongoing). For another $31 \%$, the FDA allowed the termination of the study (which may have happened when, for example, the manufacturer changed the indication for use that was the subject of the study, or when the manufacturer could demonstrate the objective of the study using publicly available data and the FDA agreed with the results). The remaining 38\% were categorized as inactive for other reasons (usually because the device was taken off the market). ${ }^{60}$ Only $2 \%$ of the post-market surveillance studies ordered were considered completed. ${ }^{61}$ Of the 40 studies still ongoing, nearly half were considered delayed. ${ }^{62}$

Notably, the post-market surveillance study system is used overwhelmingly for devices cleared through the $510(\mathrm{k})$ pathway- $94 \%$ of the 392 studies the GAO considered were for $510(\mathrm{k})$ devices. ${ }^{63}$ Given that these devices are initially cleared for marketing without any

54. Id. at 1777.

55. Id. at $1776-77$.

56. GAO-15-815, supra note 47.

57. Id. at 14 .

58. Id.

59. Id. at 15 . The $20 \%$ of studies that had been completed were completed in an average of three years. $I d$.

60. Id. at 19 .

61. Id. at 20.

62. GAO-15-815, supra note 47 , at 20 .

63. Id. at 18 . 
clinical data, it is especially concerning in these cases that the postmarket clinical studies are so inconsistently completed.

\section{B. Adverse Event Reporting}

In addition to PASs and post-market surveillance studies, the FDA also has processes in place for collecting adverse event reports on devices already on the market as part of its overall system of post-market surveillance. ${ }^{64}$ This component of the post-market regulatory regime is known as Medical Device Reporting (MDR).

The MDR system works in two ways. First, it has mandatory reporting requirements for manufacturers, importers, and device user facilities, who must report either to the FDA or to the device manufacturer after certain device-related problems occur. ${ }^{65}$ Second, it has a voluntary reporting component, whereby healthcare professionals, patients, caregivers, and consumers can submit reports of "significant adverse events or product problems" to "MedWatch," a reporting program run by the FDA. 66

As with the PASs and post-market surveillance studies, critics of the MDR system say it is under-utilized and thus contributes weakly to improving device safety. ${ }^{67}$ This may be due in part to vague language where mandatory reporting is concerned. As one commentator has noted (focusing specifically on hospitals as "device user facilities"):

Hospitals cannot be blamed fully for failures to report. The reporting requirement states that reporting is necessary if a device "may have caused death or serious illness or injury or a malfunction." The qualifier "may" throws confusion into the definition. Isaac Chang, $\mathrm{PhD}$, Director of the Division of Postmarket Surveillance at the FDA's Center for Devices and Radiological Health (CDRH), says

64. See Medical Device Reporting, U.S. Food \& Drug Admin., https://www.fda.gov/Medical Devices/Safety/ReportaProblem/default.htm (last updated Sept. 25, 2018).

65. 21 C.F.R. $\$ 803$ (2018). See Mandatory Reporting Requirements: Manufacturers, Importers and Device User Facilities, U.S. Food \& Drug Admin., https://www.fda.gov/MedicalDevices/ DeviceRegulationandGuidance/PostmarketRequirements/ReportingAdverseEvents/ucm20057 37.htm (last updated Sept. 27, 2018) (outlining the specific reporting requirements for the different entities depending on the type of adverse event).

66. Medical Device Reporting, supra note 64.

67. See, e.g., Elaine Silvestrini, FDA Change Would Weaken Already Weak Reporting System, Critics Say, DrugW ATcH, https://www.drugwatch.com/news/2018/03/01/fda-change-weaken-al ready-weak-reporting-system-critics-say/ (last updated Apr. 17, 2018) (arguing that the FDA should "take a look at its medical device reporting system" and that "the public needs more information from medical device makers"); Why "Approved" Medical Devices in the U.S. May Not Be Safe or Effective, HeAlth News Rev., https://www.healthnewsreview.org/toolkit/tipsfor-understanding-studies/medical-devices/ (last visited Jan. 31, 2019) (stating that "[m]anufacturers under-report device-related deaths, serious injuries and malfunctions" and providing examples of incidents when serious adverse events associated with specific devices went unreported). 
that a hospital does not have to provide "causality" before reporting. Almost every word of the reporting requirement can be parsed. "Serious illness or injury" means a life-threatening situation or permanent impairment, or damage to a body function or structure. Even temporary impairment dictates a report when there was quick medical or surgical intervention to prevent it from becoming permanent. And even if a "life-threatening" condition is a temporary threat, it must be reported. The "malfunction" portion of the requirement is equally ambiguous. ${ }^{68}$

And while the FDA has produced some guidance documents for manufacturers, importers, and device user facilities to follow in deciding whether to report an event, it seems these have also produced further ambiguities. ${ }^{69}$ The FDA itself has recognized that even those entities subject to the mandatory reporting requirements (such as hospitals) tend to underreport adverse events which should have been covered under 21 C.F.R. $\S 803 .{ }^{70}$ As they have characterized the problem, "[h]ospital staff often [are] not aware of, nor trained to comply with, all of the FDA's medical device reporting requirements."71 However, there has been very little responsive remedial action taken to bring underreporting entities into compliance. ${ }^{72}$ These problems are not at all new-a GAO report from 1997 focused on the same themes of noncompliance and underreporting that are still discussed today. ${ }^{73}$

Even if reporting rates were to pick up, this type of passive surveillance (wherein passive information from MDR reports is gathered into a database) is of only limited utility for improving device safety. The FDA has begun testing some pilot systems with more advanced features that would, for example, allow for electronic data submissions, automated tracking of specific devices, or the collection of more clinical data. ${ }^{74}$ However, none of these programs are yet widely used.

68. Stephen Barlas, FDA Flags Inconsistent Hospital Reporting of Medical Device Problems: Hazy Reporting Rules Beget Confusion, 42 Pharmacy \& Therapeutics 97, 97 (2017).

69. Id. at 98 .

70. A spokesman for the FDA stated in early 2016 that, "We believe that these 17 hospitals under investigation for under-reporting] are not unique in that there is limited to no reporting to the FDA or to the manufacturers at some hospitals." Id.

71. Id.

72. Id. at 115 .

73. U.S. Gov't Accountability Office, GAO/HeHS-97-21, Medical Device Reporting: Improvements Needed in FDA's System for Monitoring Problems with Approved Devices (1997). For a concrete illustration of the deficiencies in the system, consider the Riata defibrillator leads case discussed infra note 92.

74. See Barlas, supra note 68, at 99 (describing the MedSun, Sentinel, and NEST programs); Marilyn Flack et al., Identifying, Understanding, and Communicating Medical Device Use Errors: Observations from an FDA Pilot Program, in 3 Advances in Patient Safety: From ReSEARCH to IMPLEMENTATION 223 (Kerm Henriksen et al. eds., 2005) (describing and analyzing the MedSun pilot program). 
Given the difficulties the FDA has faced with obtaining compliance with the less resource-intensive, passive, information-based MDR system, it may take a substantial amount of time before hospitals or other entities move to more costly systems. ${ }^{75}$

\section{Preemption Revisited: Tort as a COMPLEMENTARy STRATEgy}

\section{A. Current State of Preemption: Supreme Court Trilogy}

As has been previously discussed, preemption of tort claims limits the scenarios in which patients injured by medical devices may turn to litigation for relief. There are doctrines of both express and implied preemption operating in this sphere that may prevent lawsuits from moving forward.

To reiterate, Riegel v. Medtronic, Inc., addressed the issue of the MDA's express preemption of state tort law claims for devices which had gone through the PMA process (Section 360k), which bars tort claims alleging that the device "violated state tort law notwithstanding compliance with the relevant federal requirements." 76 In contrast, in the previous case, Medtronic, Inc. v. Lohr, the Court held that for injuries stemming from devices which had only been cleared through the $510(\mathrm{k})$ substantial equivalence pathway (as opposed to the more rigorous PMA process), state common law claims did not face any barrier from express preemption. ${ }^{77}$

State tort law claims can also be impliedly preempted, as the Court addressed in Buckman v. Plaintiffs' Legal Committee. ${ }^{78}$ In that case, the plaintiffs did not plead traditional common law causes of action in negligence or strict liability, but instead asserted that the device's manufacturer had made fraudulent representations to the FDA, and that these representations were the but-for cause of their injuries: "had the representations not been made, the FDA would not have approved the devices, and the plaintiffs would not have been injured." 79

The Court held that such claims are preempted-not expressly by Section 360k, but nevertheless impliedly-because "the federal statutory scheme amply empowers the FDA to punish and deter fraud against the Agency, and ... this authority is used by the Agency to

75. Barlas, supra note 68 , at 115 .

76. Riegel v. Medtronic, Inc., 552 U.S. 312, 330 (2008).

77. Medtronic, Inc. v. Lohr, 518 U.S. 470, 471 (1996).

78. 531 U.S. 341 (2001).

79. Id. at 343 . 
achieve a somewhat delicate balance of statutory objectives . . . [which] can be skewed by allowing fraud-on-the-FDA claims under state tort law." 80 Notably, the applicability of implied preemption does not depend on whether the device at issue was cleared through the PMA process. In fact, the device in Buckman was a Class III device which had been cleared via the $510(\mathrm{k})$ pathway. ${ }^{81}$ Rather, the salient question is whether the plaintiff can establish a parallel state tort claim.

\section{B. Parallel State Tort Claims: Filling the Gaps}

Apart from substantial equivalence claims, the Riegel Court was careful to note that there are still claims involving FDA-regulated medical devices that will survive preemption:

State requirements are pre-empted under the MDA only to the extent that they are "different from, or in addition to" the [PMA] requirements imposed by federal law. § 360k(a)(1). Thus, § 360k does not prevent a State from providing a damages remedy for claims premised on a violation of FDA regulations; the state duties in such a case "parallel," rather than add to, federal requirements. ${ }^{82}$

In practice, finding "parallel" state tort law claims that will survive both express and implied preemption requires threading a needle and consequently is often difficult for plaintiffs. ${ }^{83}$ This may be in part because the Riegel Court itself did not specifically identify what common law causes of action would fall into the "parallel" category and survive express preemption, in part because the implied preemption doctrine articulated in Buckman was left vague, and in part because the line between express and implied preemption is itself not always clear. All of this leaves lower courts to perform their own analyses without perfect consistency across circuits. ${ }^{84}$

In Riley v. Cordis Corp., the court described the overall state of the preemption doctrine as creating only a "narrow gap" through which

80. Id. at 348 .

81. Id. at 344,346 .

82. Riegel v. Medtronic, Inc., 552 U.S. 312, 330 (2008) (quoting Lohr, 518 U.S. at 495).

83. For a parsing of the caselaw, see Jean Macchiaroli Eggen, Navigating Between Scylla and Charybdis: Preemption of Medical Device "Parallel Claims", 9 J. Health \& Biomedical L. 159 (2013).

84. Id. at 160 ("The task of sorting through these doctrines has largely been left to the lower courts, which have produced a potpourri of inconsistent and often abstruse decisions."); Demetria D. Frank-Jackson, The Medical Device Federal Preemption Trilogy: Salvaging Due Process for Injured Patients, 35 S. ILL. U. L.J. 453, 453 (2011) (noting the "continued difficulty the courts have had interpreting and applying the preemption provision of the MDA even following [the] three subsequent medical device rulings by the Supreme Court"). 
plaintiff's state-law claims "must fit if [they are] to escape" preemption. ${ }^{85}$ The court articulated a three-step test:

[T]o determine whether a claim is preempted, the Court must (1) identify the conduct that allegedly gives [the plaintiff] a right to recover damages under state law; (2) determine whether that conduct is prohibited by the FDCA (because, if it is not, the claim is expressly preempted by $\S 360 \mathrm{k}(\mathrm{a})$ ); and (3) determine whether the conduct would give rise to liability under state law even if the FDCA had never been enacted (because, if it would not, the claim is impliedly preempted under Buckman). ${ }^{86}$

Something akin to this three-step analysis seems to be at work in most opinions concerning medical device litigation, though courts differ on the precise standards for each step. In particular, courts tend to diverge when it comes to interpreting the implied preemption barsome courts have interpreted Buckman so broadly as to hold that many parallel medical device claims are impliedly preempted, ${ }^{87}$ while others read it more narrowly. ${ }^{88}$ Manufacturing defect claims ${ }^{89}$ and

85. 625 F. Supp. 2d 769, 777 (D. Minn. 2009).

86. Id. at 780 .

87. See, e.g., In re Medtronic, Inc. Sprint Fidelis Leads Product Liability Litigation, 592 F. Supp. 2d 1147, 1161 (D. Minn. 2009), aff'd sub nom. Bryant v. Medtronic, Inc., 623 F.3d 1200 (8th Cir. 2010) ("[W]hen Sections 337(a) and 360k(a) - as construed in Buckman and Riegel, respectively_are read together, nearly all types of claims concerning FDA-approved medical devices are preempted, including Plaintiffs' failure-to-warn claims here.”)

88. For example, the Fifth, Seventh, and Ninth Circuits hold that plaintiffs who assert recognized state tort claims should not be considered impliedly preempted as a result of Buckman's holding. Stengel v. Medtronic, Inc., 704 F.3d 1224, 1233 (9th Cir. 2013).

89. See, e.g., Bass v. Stryker Corp., 669 F.3d 501, 511-12 (5th Cir. 2012) ("[I]f a plaintiff pleads that a manufacturer of a Class III medical device failed to comply with either the specific processes and procedures that were approved by the FDA or the [current Good Manufacturing Practices] themselves and that this failure caused the injury, the plaintiff will have pleaded a parallel [manufacturing defect] claim."); Bausch v. Stryker Corp., 630 F.3d 546, 549 (7th Cir. 2010) (manufacturing defect claim implicating a violation of the FDA's Good Manufacturing Practices was allowed to proceed); Howard v. Sulzer Orthopedics, Inc., 382 Fed. App'x 436, 437-38 (6th Cir. 2010) (same); Warren v. Howmedica Osteonics Corp., No. 4:10 CV 1346 DDN, 2011 WL 1226975 (E.D. Mo. Mar. 29, 2011) (same).

However, those claims that rest on violations of the FDA's Good Manufacturing Practices are sometimes barred, in part because the GMPs are not device-specific and the FDA regulations give manufacturers some flexibility and independence to establish procedures to meet them. Ilarraza v. Medtronic, Inc., 677 F. Supp. 2d 582 (E.D.N.Y. 2009), illustrates the problem generally found with such claims. In that case, the plaintiff alleged that a defective medication pump caused his injuries after the manufacturer violated several specific GMP regulations. The district court held that because "these regulations are open to a particular manufacturer's interpretation, allowing them to serve as a basis for a claim would lead to differing safety requirements that might emanate from various lawsuits," the manufacturing defect claims that hinged on the GMP violations were preempted. Id. at 588. See also In re Medtronic, 592 F. Supp. 2d at 1157 (finding the GMPs are "simply too generic, standing alone, to serve as the basis for Plaintiffs' manufacturing-defect claims"). 
failure to warn claims, ${ }^{90}$ especially, can sometimes survive as parallel claims.

The failure of St. Jude Medical's Riata defibrillator leads resulted in a raft of litigation and offers a representative example of how tort claims may at times serve in a complementary regulatory capacity for medical devices. Riata was a Class III device, which had gone through the PMA process (including fourteen PMA supplements between 1996 and 2002 to arrive at the device at issue). ${ }^{91}$ It was recalled after St. Jude found that internal cables were poking through its outer casing, causing unwanted shocks or the failure of the device to work when needed. ${ }^{92}$ Some of these cases had their claims dismissed as preempted, ${ }^{93}$ but others survived motions to dismiss (and often ended in settlements ${ }^{94}$ ).

90. See, e.g., Hughes v. Boston Scientific, 631 F.3d 762, 769-71 (5th Cir. 2011) ("To the extent that Hughes asserts a failure to warn claim based only on Boston Scientific's failure to comply with FDA regulations ... . such a claim is not expressly preempted . . . . This claim does not impose additional or different requirements to the federal regulations, but is parallel to the federal requirements.").

91. Rosen v. St. Jude Med., Inc., 41 F. Supp. 3d 170, 174 (N.D.N.Y. 2014); Marmol v. St. Jude Med. Ctr., 132 F. Supp. 3d 1359, 1361 (M.D. Fla. 2015).

92. Katie Thomas, Unpredictable Danger Looms Close to the Heart, N.Y. Times, Sept. 7, 2012, at A1. It is worth noting that the Riata saga also offers a case study showcasing some of the failures of post-market monitoring: Although St. Jude reported in November 2011 that there was a problem with the leads, it announced publicly that it only affected $1 \%$ of patients. An internal report by an FDA employee argued that the company was underestimating the problem, but that report was not made public. It was only in July 2012 that a new study was performed which made clear that the Riata device was actually showing signs of failure for nearly $20 \%$ of patients. That August, the FDA recommended that all patients with the Riata still implanted undergo imaging to see if their lead was failing-but heart device specialist doctors interviewed for a September New York Times article had not all heard of the new recommendations. $I d$. The delay in calling for the recall may have been due to the weak adverse event reporting system in place. The FDA found that as of 2009, St. Jude Medical had "failed to submit [Medical Device Reporting] reports containing all information reasonably known to them in accordance" with the regulations governing adverse event reporting. Rosen, 41 F. Supp. 3d at 174.

93. See, e.g., Marmol, 132 F. Supp. 3d at 1370 (holding plaintiff's failure-to-warn and manufacturing defect claims preempted because they were premised upon violations of FDA regulations without parallel violations of a Florida-law duty).

94. See, e.g., Marie Thibault, St. Jude Medical Settles, Closing Out Riata Suits, Med. Device \& Diagnostic Industry (Feb. 27, 2015), https:/www.mddionline.com/st-jude-medical-settlesclosing-out-riata-suits (discussing St. Jude's 2015 settlement of approximately 950 cases for an estimated \$14.25 million).

Prior to the settlement, in Rosen, the plaintiff successfully alleged that defendants failed to comply with FDA reporting requirements concerning known adverse events, which was a violation of a federal duty that paralleled New York's duty to exercise reasonable care in warning of potential dangers (so the claim was not expressly preempted). 41 F. Supp. 3d at 185 . The court adhered to the narrower reading of Buckman, agreeing with the plaintiff that it only stood "for the proposition that a plaintiff cannot bring suit based solely on a violation of the FDCA," and that "a defendant may still be liable under state law" for failure to warn (so the claim was not impliedly preempted). $I d$. at 186 . The court also held that the plaintiff "sufficiently pled a parallel state claim" for manufacturing defects (in negligence and strict liability). Id. at 181 . 


\section{Concluding Observation: The Salience of Reform at the Agency Level}

Given the general strength of the preemption bar, it is clear that tort can only play a limited, complementary role in improving the safety of medical devices on the market. Apart from 510(k) substantial equivalence claims, plaintiffs must be able to allege parallel state tort claims that will survive both express and implied preemption in order to proceed to the merits of any given case-a tightrope that can be difficult to walk.

As such, reform at the agency level will be the more powerful strategy in improving device safety. To this end, it is critical that the FDA moves forward on multiple fronts: Assuring, at the threshold that its high-risk classifications are in fact well-founded;95 demonstrating a commitment to clinical methodology (in PMA cases) that goes beyond the formalistic recitations of competence in the Riegel preemption decision; and adhering to clear guidelines (and standards) in monitoring post-marketing device performance. Public health concerns warrant no less.

More recently, a plaintiff sued St. Jude with a single failure to warn claim under Pennsylvania law, after her Riata lead malfunctioned by firing six times while she was in a plane on the tarmac. Bull v. St. Jude Med., Inc., No. 17-1141, 2018 U.S. Dist. LEXIS 115730, at *14 (E.D. Pa. July 12, 2018). This court also held that her claim was neither expressly nor impliedly preempted, opting for the narrow reading of Buckman: For the "simple fact" that "Plaintiff's cause of action is a traditional state failure to warn theory premised on alleged non-compliance with federal regulations," it was not impliedly preempted. $I d$. at $* 28$.

95. Dr. Redberg points out that: "[M] any high-risk devices, were classified as Class II, an intermediate risk category, meant to be used for some high-risk devices on a temporary basis in 1976. Forty years later, high risk devices remain in the intermediate risk pathway, while some have been reclassified as lower risk Class II devices." Redberg, Improving the Safety of HighRisk Medical Devices, supra note 22, at 